\title{
Ultrafast and Controllable Phase Evolution by Flash Joule
}

\section{Heating-Supporting Information}

Weiyin Chen, ${ }^{1}$ John Tianci Li, ${ }^{1,2}$ Zhe Wang, ${ }^{1}$ Wala A. Algozeeb, ${ }^{1}$ Duy Xuan Luong, ${ }^{1}$ Carter

Kittrell, ${ }^{1}$ Emily A. McHugh, ${ }^{I}$ Paul A. Advincula, ${ }^{1}$ Kevin M. Wyss, ${ }^{1}$ Jacob L. Beckham, ${ }^{I}$ Michael

G. Stanford, ${ }^{1}$ Bo Jiang, ${ }^{1}$ and James M. Tour ${ }^{1,2,3,4^{*}}$

${ }^{1}$ Department of Chemistry, ${ }^{2}$ Department of Materials Science and NanoEngineering, ${ }^{3}$ Smalley-

Curl Institute, NanoCarbon Center, the Welch Institute for Advanced Materials and ${ }^{4}$ Department

of Computer Science, Rice University, 6100 Main Street, Houston, Texas 77005, USA

*Email: tour@rice.edu

Flash Joule Heating (FJH) Setup
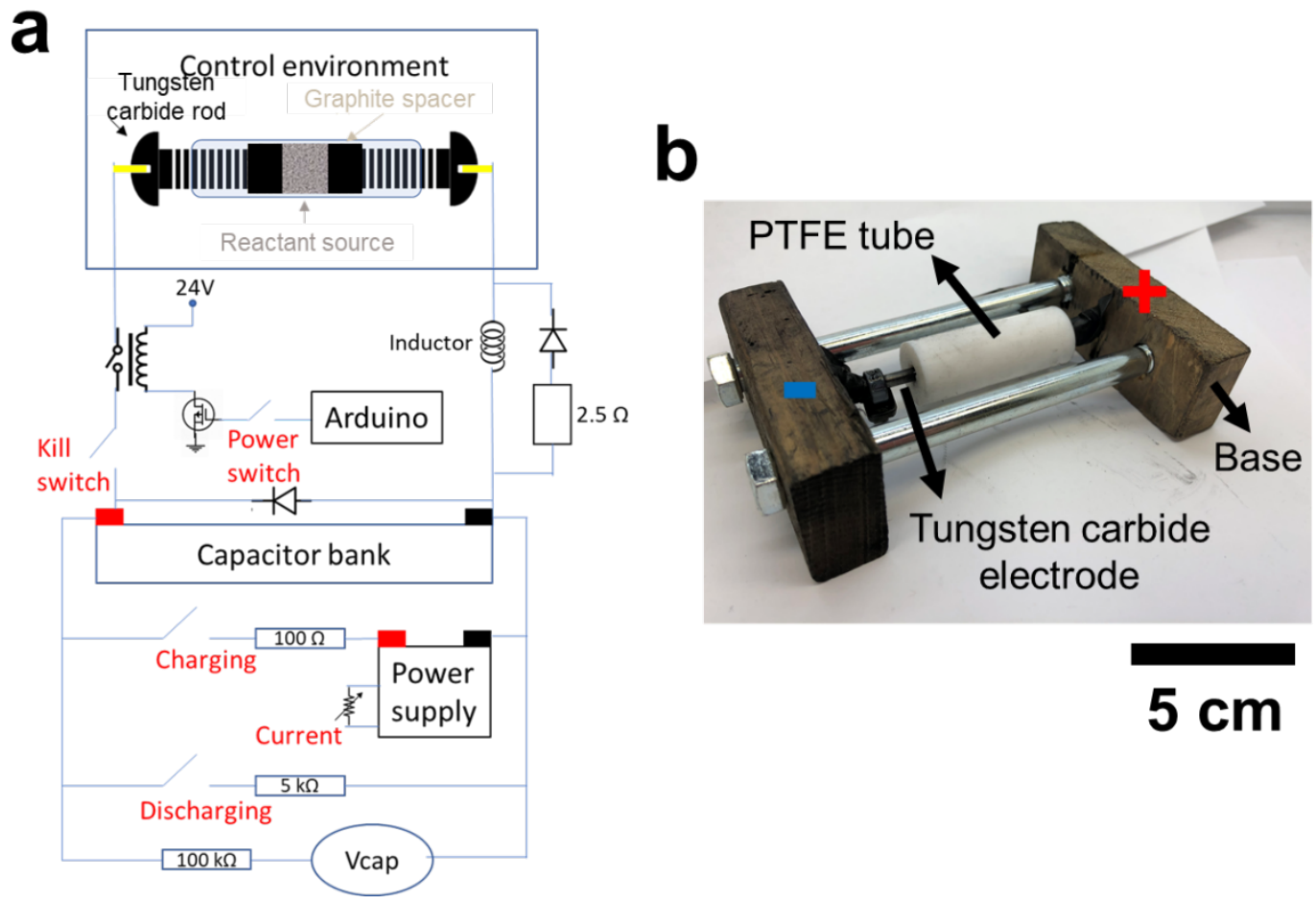

Figure S1. (a) The circuit diagram of the FJH setup. The circuit diagram is adapted from our previous publication. ${ }^{1,2}$ (b) The photo of the FJH pressure reactor box. 
The home-made high pressure FJH reaction box was composed of a wooden base, two rotary knobs and two electrodes connected with wires to the circuit. The applied pressure can be adjusted by the rotary knobs at the two ends. The tighter the tungsten carbide electrodes compress the sample, the higher pressure the system can build up during the flash reaction. Instead of using quartz tubes to hold the reactants as in our previous work, the tube used here was a polytetrafluoroethylene (PTFE) tube with thick wall $(\sim 1 \mathrm{~cm})$ so as to reduce damage to the tube and to hold high pressures during the FJH reaction. The prepared powder sample was placed between the two graphite spacers that directly contact the tungsten carbide electrodes. The reactants were compressed until the desired resistance was reached. The flash parameters are described in the Experimental Section and Table 2.

The circuit diagram of the FJH setup is shown in Figure S1a. The electrical energy used to discharge the sample was from the capacitor bank with a total capacitance of $60 \mathrm{mF}$. The capacitor bank was charged by a d.c. power supply that could reach $400 \mathrm{~V}$. An Arduino controller relay with programmable millisecond-level delay time was used to control the discharge time, and the electric energy was provided by the capacitor bank. Safety glasses designed for welding are generally suitable and recommended during the flash reaction because they effectively block infrared as well as ultraviolet light. More safety notes follow. ${ }^{1,3}$

\section{SAFETY NOTES ${ }^{1,3}$}

Flash Joule heating (FJH) involves high currents and voltages, which involves a potential risk of electrical shock or even electrocution, so these features should be implemented. This list is not intended to be comprehensive, but demonstrative of the protocols needed to minimize risk. 
1. Enclose or carefully insulate all wire connections.

2. All connections, wires and components must be suitable for the high voltages and currents.

3. Be aware that component failure could cause high voltage to appear in unexpected places, such as heat sinks on the switching transistors.

4. Control wires should have opto-isolators rated for high voltage.

5. Provide a visible charge indicator. A $230 \mathrm{~V}$ clear glass incandescent light bulb is a good choice as the glow on the filament also provides an approximate indicator of the amount of charge on the capacitor bank. Bright light = danger!

6. Do not use toggle switches with metal toggles. If an arc develops, the metal toggle could become charged.

7. One hand rule. Use only one hand when working on the system, with the other hand not touching any grounded surface.

8. Install bleed resistors in the range of $100,000 \mathrm{ohms}$ on each capacitor so that charge will always bleed off in $\sim 1 \mathrm{~h}$.

9. Provide a mechanical discharge circuit breaker switch connected to a power resistor of a few hundred ohms to rapidly bleed off the capacitor charge.

10. Provide a "kill" circuit breaker switch to disconnect the sample holder from the capacitor bank.

11. Provide an AC disconnect circuit breaker switch.

12. Post high voltage warning signs on the apparatus.

13. Use of circuit breakers as switches. Circuit breakers have built-in arc suppression that can interrupt 1000 amps or more. Conventional switches do not have such a high level of arc suppression and can burn out or weld closed due to the high current pulses. 
14. Use circuit breakers rated for DC voltage. Most AC circuit breakers have a DC rating $1 / 2$ the voltage or less, since DC arcs are much more difficult to suppress. Circuit breakers designed for DC solar power systems are a good choice.

15. When choosing circuit breakers, choose by the time curves typical for $0.1 \mathrm{~s}$, rather than the steady state current rating. K-type DC circuit breakers will have $\sim 10 \mathrm{x}$ higher trip current at $0.1 \mathrm{~s}$ compared to their rated current, and Z-type breakers will have $\sim 4 \times$ higher trip current at $0.1 \mathrm{~s}$. This "delayed trip" designed into most circuit breakers will allow much higher pulse currents than the steady state rating of the breaker.

16. Include a small amount of inductance in the discharge circuit to limit the rise time to a millisecond or more. Extremely fast discharges can damage components and cause RF interference with other lab apparatus.

17. Keep in mind that the system can discharge many thousands of Joules in milliseconds, which can cause components such as relays or even capacitors to explode. These components should be enclosed to protect against both high voltage and possible flying debris.

18. Keep a voltmeter with high voltage test leads handy at all times. When working on the capacitor bank, always check the voltage on each. A broken wire or loose connection could leave the capacitor in a charged state.

19. Wear thick rubber gloves extending to the elbows when using the apparatus to protect from electrocution.

20. All users should be properly trained by an experienced electrical technician.

21. Have a qualified electrical engineer inspect the instrument for safety before its use and reinspect it weekly for users. 

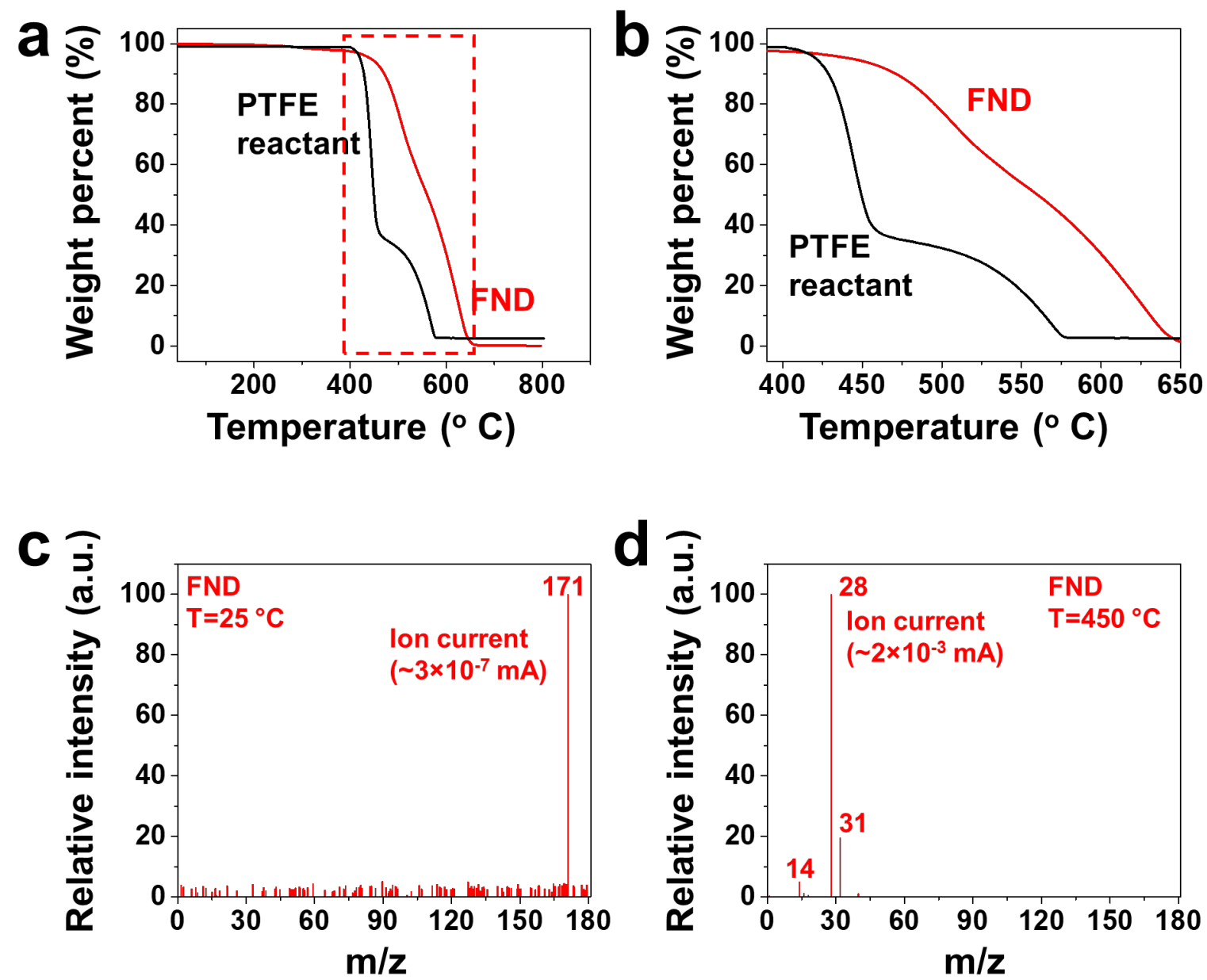

Figure S2. (a) TGA curve of FND (red) and PTFE reactant (black). (b) Detailed TGA curve from $400 \sim 650{ }^{\circ} \mathrm{C}$. (c) Mass spectrum of FND sample at $25^{\circ} \mathrm{C}$. (d) Mass spectrum of FND sample at $450{ }^{\circ} \mathrm{C}$. TGA and DSC data was collected from 25 to $800{ }^{\circ} \mathrm{C}$ under air. The heating rate was set to $10^{\circ} \mathrm{C} / \mathrm{min}$ from 25 to $400{ }^{\circ} \mathrm{C}, 1^{\circ} \mathrm{C} / \mathrm{min}$ from 400 to $700^{\circ} \mathrm{C}$, and $10{ }^{\circ} \mathrm{C} / \mathrm{min}$ from 700 to $800{ }^{\circ} \mathrm{C}$. The air flow was maintained at $80 \mathrm{~mL} / \mathrm{min}$ throughout the run. For the PTFE reactant (PTFE and $20 \mathrm{wt} \% \mathrm{CB}$ ), two obvious stages can be distinguished: (1) $400 \sim 465{ }^{\circ} \mathrm{C}$, related to the thermal decomposition of PTFE and (2) $465 \sim 580{ }^{\circ} \mathrm{C}$, corresponding to the oxidation of carbon black. In contrast, after the FJH process, FND showed near-continuous stage, with a gradual change after $\sim 550{ }^{\circ} \mathrm{C}$, which corresponding to the TEM images as shown in Figure 2, where the FNDs were 
found embedded in the AC substrate. There is no thermal decomposition at $25^{\circ} \mathrm{C}$ for FND sample and the ion current is attributed from the background at shown in Figure S2c. When the temperature goes to $450{ }^{\circ} \mathrm{C}$, there are three major $\mathrm{m} / \mathrm{z}$ peaks at 28,31 and 14 , respectively (Figure S2d). For the thermal decomposition of PTFE, over $400{ }^{\circ} \mathrm{C}$, pyrolysis occurs, and the main decomposition products are tetrafluoroethylene $\left(\mathrm{F}_{2} \mathrm{C}=\mathrm{CF}_{2}\right)$ and difluorocarbene radicals $\left(\mathrm{RCF}_{2}\right){ }^{4}$ Consequently, there are several $\mathrm{m} / \mathrm{z}$ peaks at $50,69,81$ and 100 . The absence of these peaks in the FND samples indicate that there is no amorphous PTFE residue in the products. 



Figure S3. TEM images of FNDs after the TGA treatment. In order to thermally purify the FND sample, the temperature was kept at $550{ }^{\circ} \mathrm{C}$ for $30 \mathrm{~min}$ instead of increasing to $>800{ }^{\circ} \mathrm{C}$. Other conditions were the same including the heating rate and air flow. The crystallinity of the FNDs was high and there was no obvious amorphous carbon at the edge of the crystal, which indicates that thermal treatment could be an effective method to purify the FND samples. Figure S3d shows the formation of polyhedral CC structures in some areas, which was the result of graphitization. 

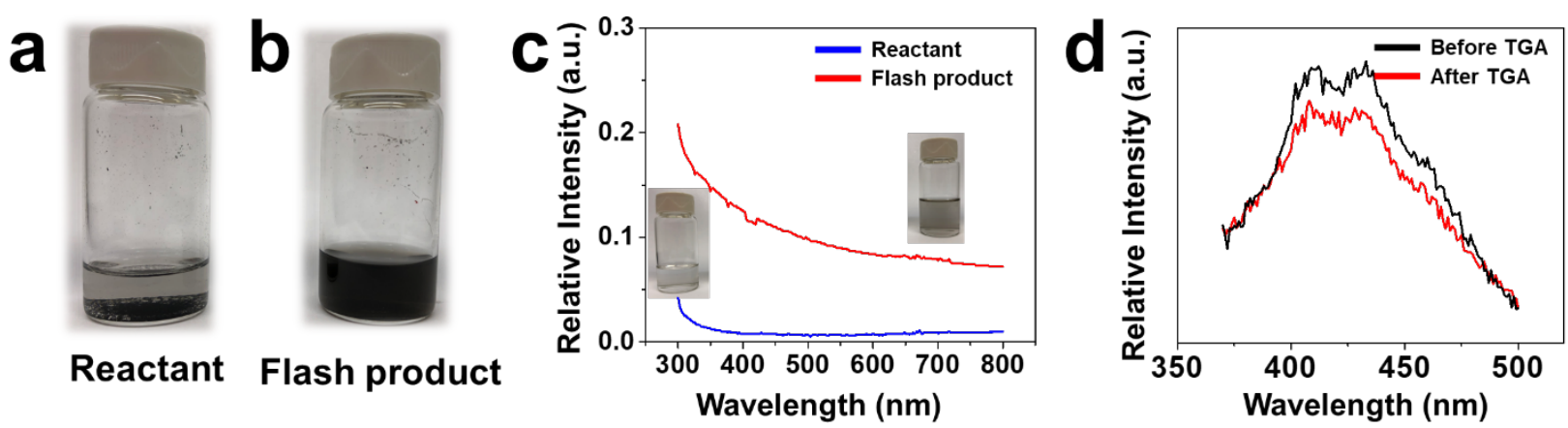

Figure S4. Optical images of (a) reactant mixture (PTFE and $20 \mathrm{wt} \% \mathrm{CB}$ ) and (b) flash product in ethanol with an initial concentration of $4 \mathrm{mg} / \mathrm{mL}$. The photos were taken after standing for 10 days. (c) UV-vis spectra of the corresponding mixtures after $20 \times$ dilutions. The respective optical images can be seen in the insets. The dispersion test and the UV-vis result show that the flash product had a better dispersibility, good for potential application as lubricant additives. ${ }^{1,5}$ (d) Photoluminescence spectra of FND samples before and after thermal treatment. The PL peaks at the range of $400-470 \mathrm{~nm}$ can be distinguished from the spectra. ${ }^{6}$ The current quantum yield is $<1 \%$, which can be attributed to the size effect of FND and quenching effect from the small amount of carbon allotropes.

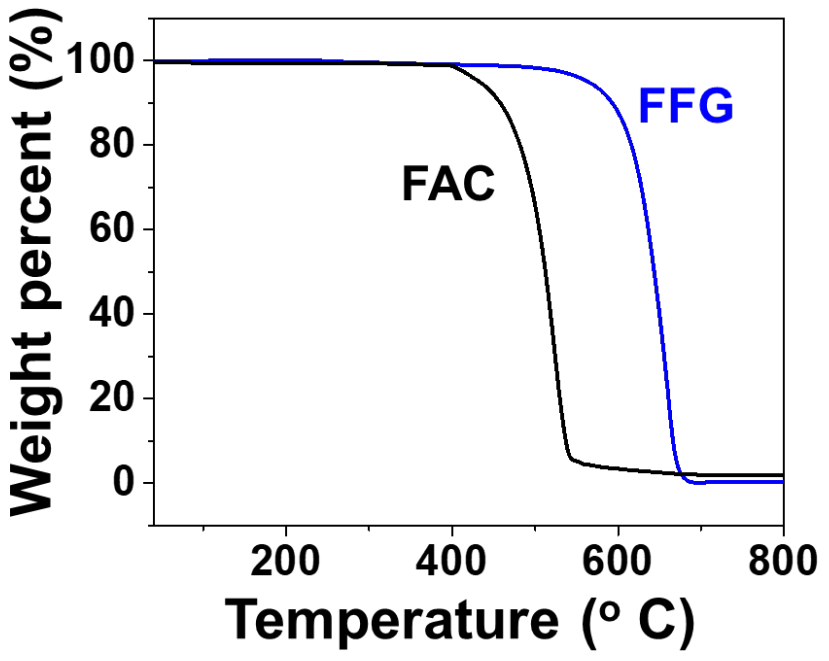


Figure S5. TGA curve of FFG (blue) and FAC (black). TGA and DSC data was collected from 25 to $800{ }^{\circ} \mathrm{C}$ under air. The heating rate was set to $10^{\circ} \mathrm{C} / \mathrm{min}$ from 25 to $400{ }^{\circ} \mathrm{C}, 1{ }^{\circ} \mathrm{C} / \mathrm{min}$ from 400 to $700{ }^{\circ} \mathrm{C}$, and $10{ }^{\circ} \mathrm{C} / \mathrm{min}$ from 700 to $800{ }^{\circ} \mathrm{C}$. The air flow was maintained at $80 \mathrm{~mL} / \mathrm{min}$ throughout the run. As shown here, the thermal decomposition temperature of $\mathrm{FFG}$ is $\sim 150{ }^{\circ} \mathrm{C}$ higher than FAC, thus, the thermal stability of the crystalline FFG is higher than amorphous FAC.

The purity of FFG can reach $>90 \%$ since there is only one stage of the mass loss. The conclusion is consistent with the TEM images as shown in Figures 1 and 2. FNDs are embedded in the amorphous carbon substrate and the purity of FNDs is at least $30 \%$. TEM images of the FND sample after TGA treatment shows the removal of the amorphous carbon substrate and the existence of the NDs. An estimation of the sample yield is calculated based on eq 1:

Yield $=\frac{m_{\text {flash product }}}{m_{\text {reactant }}} \times \frac{m_{\text {TGA-final }}}{m_{T G A-s t a r t}}$

Here, $m_{\text {reactant }}$ and $m_{\text {flash product }}$ refer to the mass of the reactant and flash product in the flash reaction. $m_{T G A-s t a r t}$ and $m_{T G A-f i n a l}$ refer to the mass before and after the TGA thermal treatments. The estimated yields of FND and FFG are $\sim 15 \%$ and $\sim 40 \%$, respectively.

\section{Spectroscopic analysis of the carbon materials at different stages}



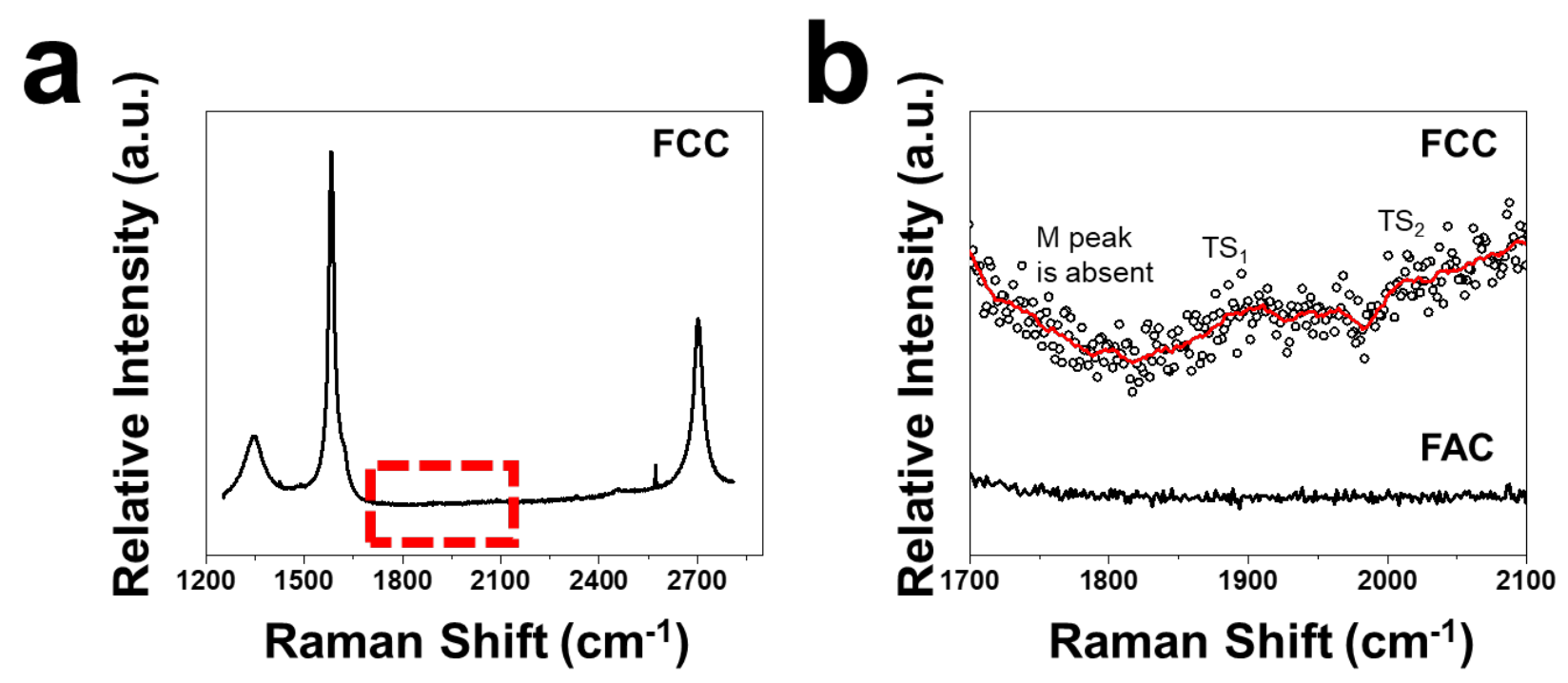

Figure S6. (a) The Raman spectrum of FCC. (b) The corresponding high-resolution Raman spectrum of FCC. The high-resolution Raman spectrum of FAC is given as a reference. Compared to the FFG as shown in Figure $3 \mathrm{a}$ and $3 \mathrm{c}$, FCC has a lower $2 \mathrm{D} / \mathrm{G}$ ratio $(\sim 0.55)$ and weaker turbostratic Raman signals ( $\mathrm{TS}_{1}$ and $\mathrm{TS}_{2}$ peaks). There is still no obvious $\mathrm{M}$ peak in the highresolution Raman spectrum of the FCC material, which indicates that there might be some substacking sequence along the $\mathrm{c}$ axis rather than $\mathrm{AB}$ (Bernal) stacking or random stacking. The peak positions of the $\mathrm{G}$ and $2 \mathrm{D}$ peaks are 1580 and $2701 \mathrm{~cm}^{-1}$, respectively, and there was no obvious downshift compared to graphene sheets, which excludes the existence of fullerene shell and strong strain in FCC polyhedral structure. 

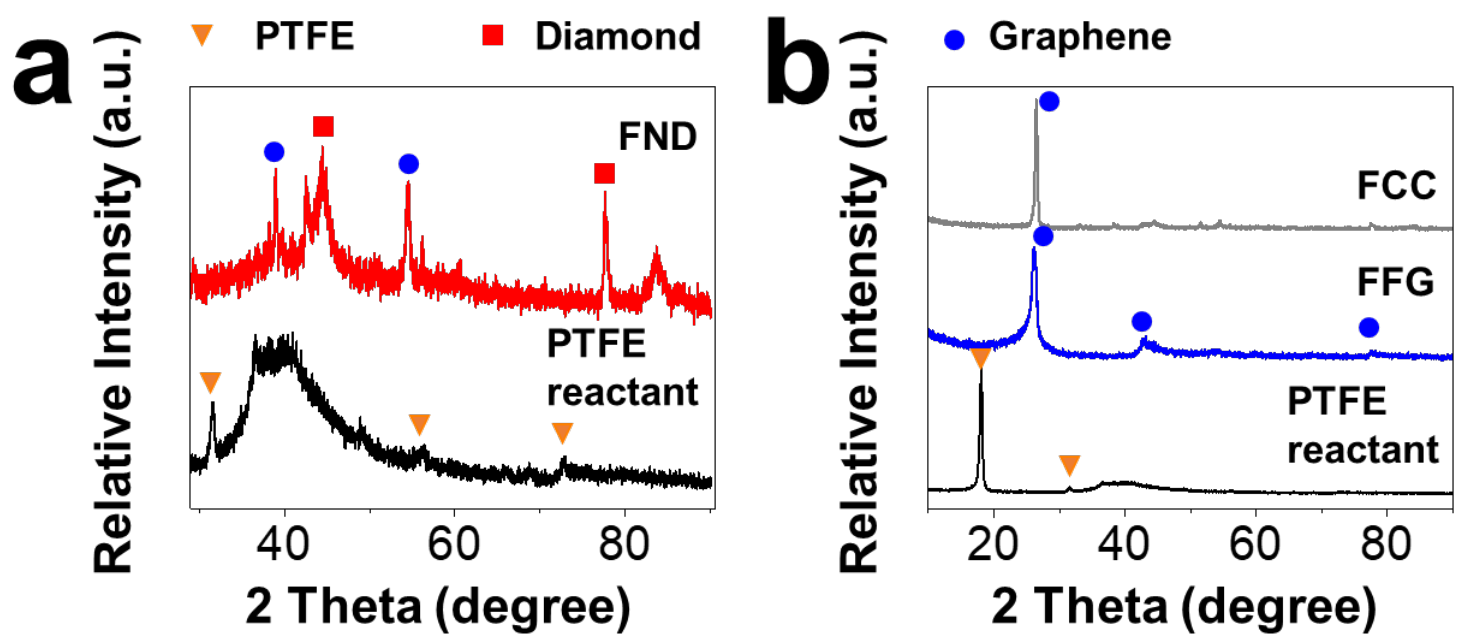

Figure S7. (a) XRD results of FND (red) and PTFE reactant (black). (b) XRD results of FCC (gray), FFG (blue) and PTFE reactant (black). Powder Diffraction File: 04-022-7811, diamond, C. 04-016-0554, graphene, C. 00-047-2217, PTFE.

As shown in Figure S7a, the (111) and (220) diffraction peaks of the diamonds can be distinguished which confirms the existence of the nanodiamonds in the FND sample. The (002) diffraction peak in the FFG sample become broader, which indicates the turbostratic nature of the graphene in the FFG sample. On the contrary, the (002) peak in the FCC sample is narrow and the intensity of the peak is much stronger than (100) and other diffraction peaks. This is attributed to the long-order staking along the $\mathrm{Z}$ axis in FCC sample. 
Table S1 Various element content in different carbon allotropes and fluoropolymers as determined by XPS survey spectral analysis.

\begin{tabular}{cccc}
\hline & Carbon & Fluorine & Oxygen \\
\hline PTFE & $33.1 \%$ & $66.9 \%$ & 0 \\
FG & $99.3 \%$ & 0 & $\sim 0.7 \%$ \\
FFG & $92.6 \%$ & $7.4 \%$ & 0 \\
FND & $80.0 \%$ & $20.0 \%$ & 0 \\
FCC & $96.1 \%$ & $2.7 \%$ & $1.1 \%$ \\
PVDF & $50.5 \%$ & $49.5 \%$ & 0 \\
\hline
\end{tabular}

As shown in Figure S9-S10 and Figure 4, the content of various elements can be calculated based on the integral area of each elements. Table S1 reports the element content in the fluoropolymers and different carbon allotropes as determined by XPS survey spectra. 



Figure S8. The XPS analyses of PTFE, FFG and FND samples. The high-resolution C KLL spectra of (a) PTFE, (c) FFG and (e) FND samples; (b), (d) and (f) are the corresponding derivative curves of the C KLL spectra in (a), (c) and (e). 

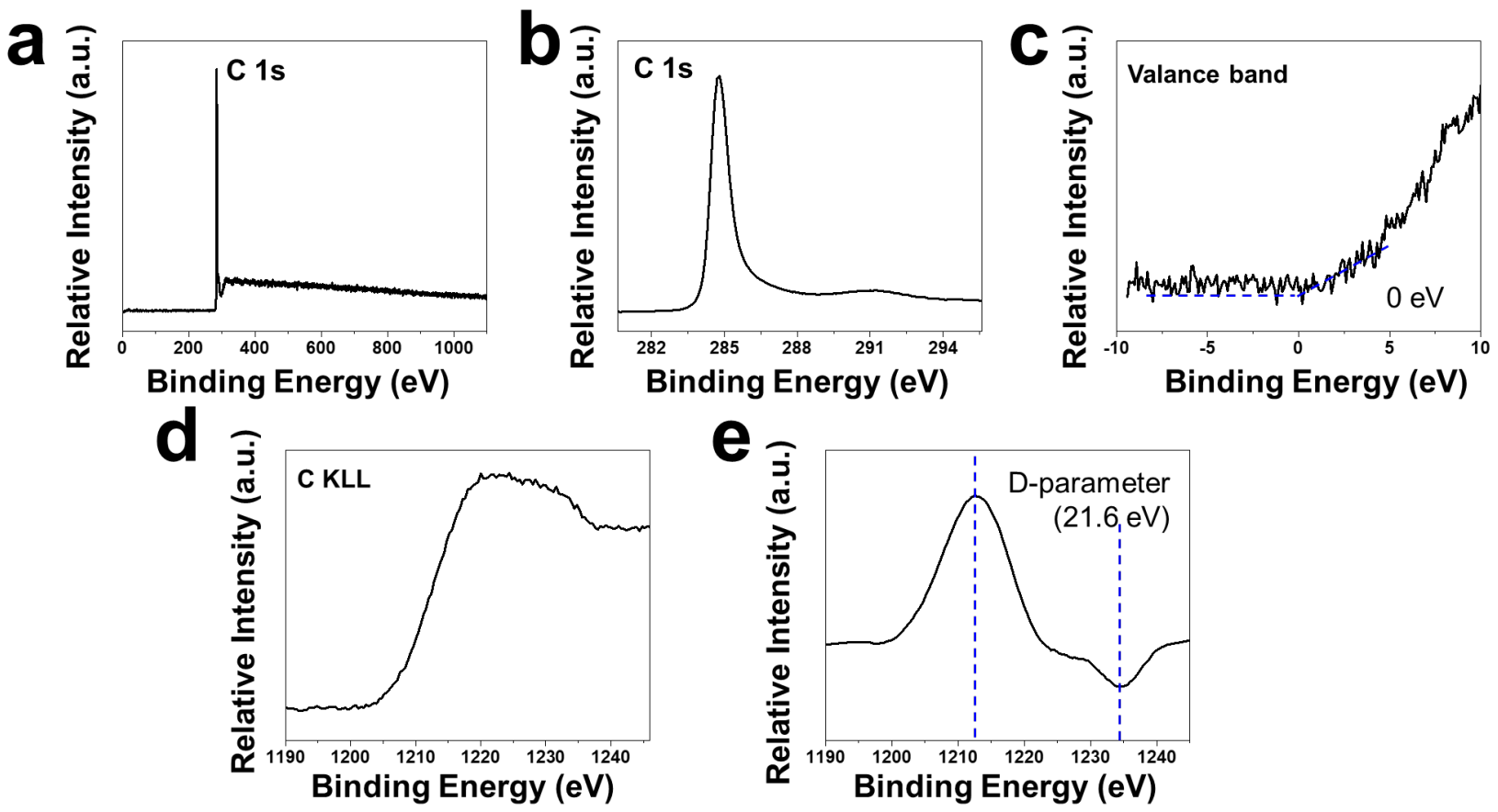

Figure S9. The XPS analysis of FG without fluorine addition. (a) XPS spectrum of FG without fluorination. High resolution XPS spectra of (b) C 1s, (c) valance band and (d) C KLL of FG without fluorination. (e) The derivative curve of the C KLL spectrum in (d). There is no detectable impurity other than carbon from the survey scan shown in Figure S9a. From Table S1, the carbon content is more than $99 \%$ and there is only $\sim 0.7 \% \mathrm{O}$ in the FG without fluorination. The VB-XPS has further shown the bandgap of the FG without fluorination is $0 \mathrm{eV}$ in Figure S9c. The Dparameter measures the energy difference between maxima and minima in differentiated C KLL spectra as shown in Figure S9e. In diamond (mainly $\mathrm{sp}^{3}$-carbon), the D-parameter value is $\sim 13 \mathrm{eV}$, while graphite with $\mathrm{sp}^{2}$-carbon can reach more than $21 \mathrm{eV}$. The larger D-parameters infer higher $\mathrm{sp}^{2}: \mathrm{sp}^{3}$ ratios. Here the D parameter for the FG was $21.6 \mathrm{eV}$, which indicates a high $\mathrm{sp}^{2}: \mathrm{sp}^{3}$ ratio. 

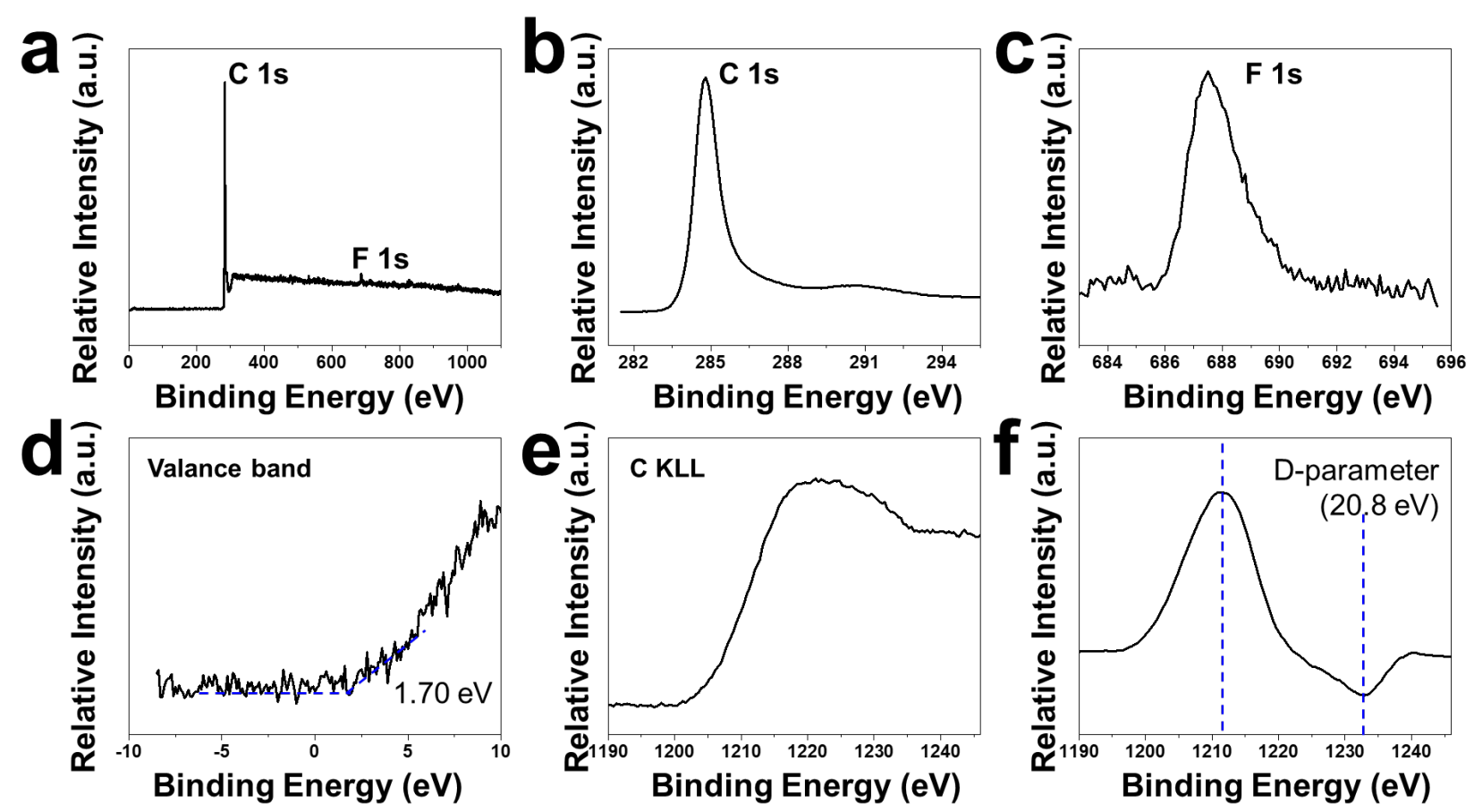

Figure S10. The XPS analysis of FCC. (a) XPS spectrum of FCC. High resolution XPS spectra of (b) C 1s, (c) F 1s, (d) valance band and (e) C KLL of FCC materials. (f) The derivative curve of the C KLL spectrum in (e). There is $96.1 \%$ carbon and $\sim 4 \%$ of heteroatoms, such as F (mainly semi-ionic C-F bonds) and $\mathrm{O}$ in the samples as shown in Figure S10 and Table S1. The VB-XPS further shows the bandgap of the FCC material is $1.70 \mathrm{eV}$ in Figure $\mathrm{S} 10 \mathrm{~d}$, which can result from binding with heteroatoms, such as $\mathrm{F}$, and the discontinuity of the conjugated $\mathrm{C}=\mathrm{C}$ structure. The D parameter was $20.8 \mathrm{eV}$ as shown in Figure S10f which also indicates a small portion of $\mathrm{sp}^{3}$ carbon atoms in the sample. 
Table S2 Bandgap and D-parameter in different carbon allotropes and reactants as determined by C KLL XPS analyses.

\begin{tabular}{ccc}
\hline & Bandgap & D-parameter \\
\hline PTFE & $4.08 \mathrm{eV}$ & $13.4 \mathrm{eV}$ \\
FG & $0 \mathrm{eV}$ & $21.6 \mathrm{eV}$ \\
FFG & $1.78 \mathrm{eV}$ & $20.6 \mathrm{eV}$ \\
FND & $5.50 \mathrm{eV}$ & $16.0 \mathrm{eV}$ \\
FCC & $1.70 \mathrm{eV}$ & $20.8 \mathrm{eV}$ \\
PVDF & $3.30 \mathrm{eV}$ & $14.4 \mathrm{eV}$ \\
\hline
\end{tabular}

As shown in Table S2, the reactant PTFE has the lowest D parameter $(13.4 \mathrm{eV})$, since it is composed of $\mathrm{C}-\mathrm{C}$ bonds and $\mathrm{C}-\mathrm{F}$ bonds; this indicates that there is a large proportion of $\mathrm{sp}^{3}$-carbon in the reactant. The FND sample that showed individual NDs, the majority of which are embedded in the amorphous carbon substrate or coated with a graphene shell, shows some portion of $\mathrm{sp}^{2}-$ carbon and the D-parameter was $16.0 \mathrm{eV}$. The FFG and FCC materials are mainly composed of $\mathrm{C}=\mathrm{C}$ conjugated structures while the edge can be functionalized with heteroatoms, such as $\mathrm{F}$ or $\mathrm{O}$, which show larger D-parameters, $20.6 \mathrm{eV}$ in FFG and $20.8 \mathrm{eV}$ in FCC materials. 


\section{Effect of flash reactants on phase evolution of carbon materials}
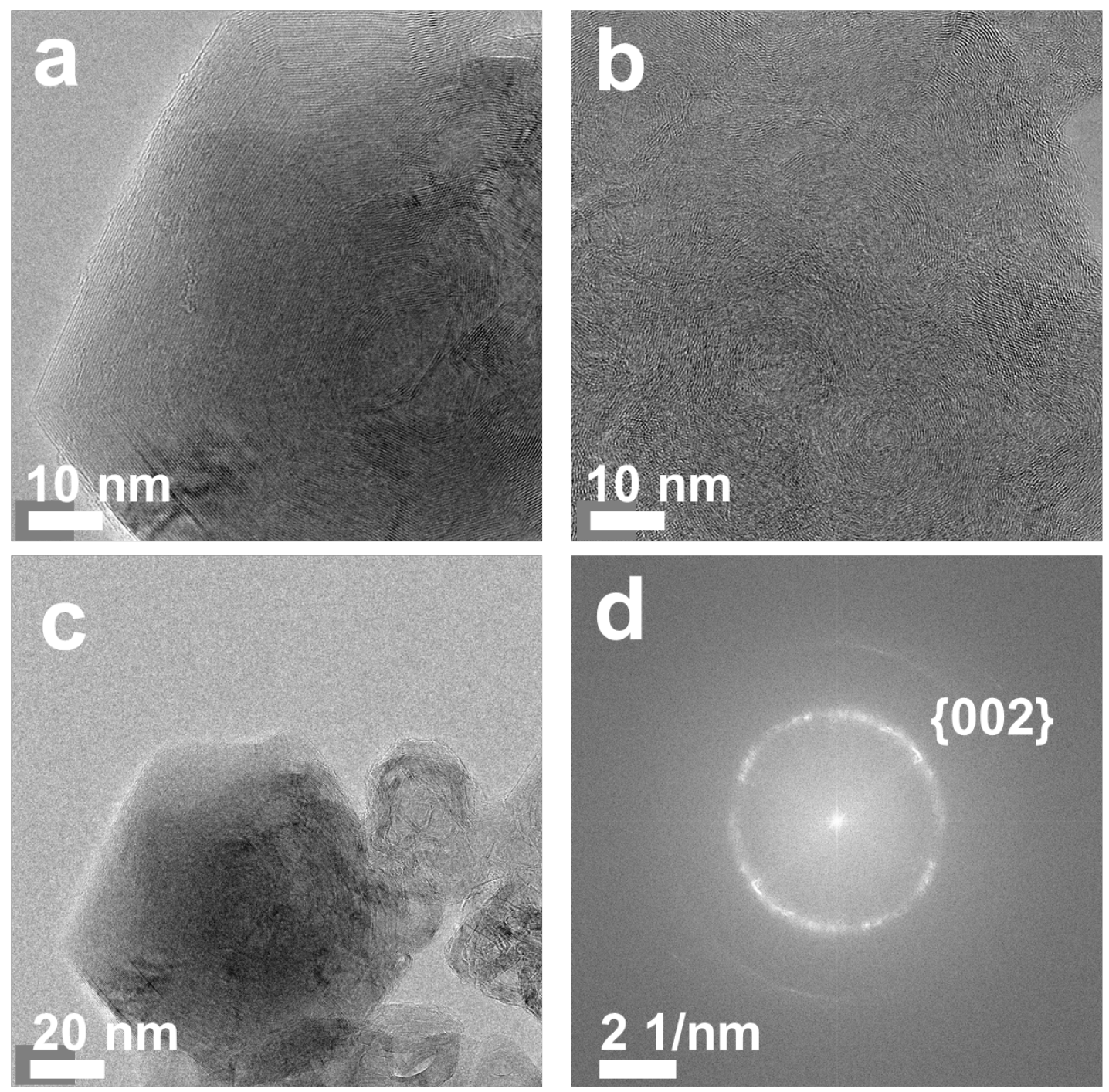

Figure S11. Microscopic analysis of carbon materials from PVDF with 20 wt\% CB. (a-b) HRTEM images of the CC materials. (c) TEM images of CC materials and (d) the corresponding FFT result. The spacing of $\{002\}$ plane is $\sim 0.36 \mathrm{~nm}$, which is larger than common AB-stacking graphene sheet. In the center of the $\mathrm{CC}$, some highly ordered carbon clusters can be seen with circular shapes as shown in Figure S11b. There are several sets of diffraction spots in the FFT images, which indicates the stacking mismatch along the c axis and turbostratic nature of the product derived from PVDF with $20 \mathrm{wt} \% \mathrm{CB}$. 

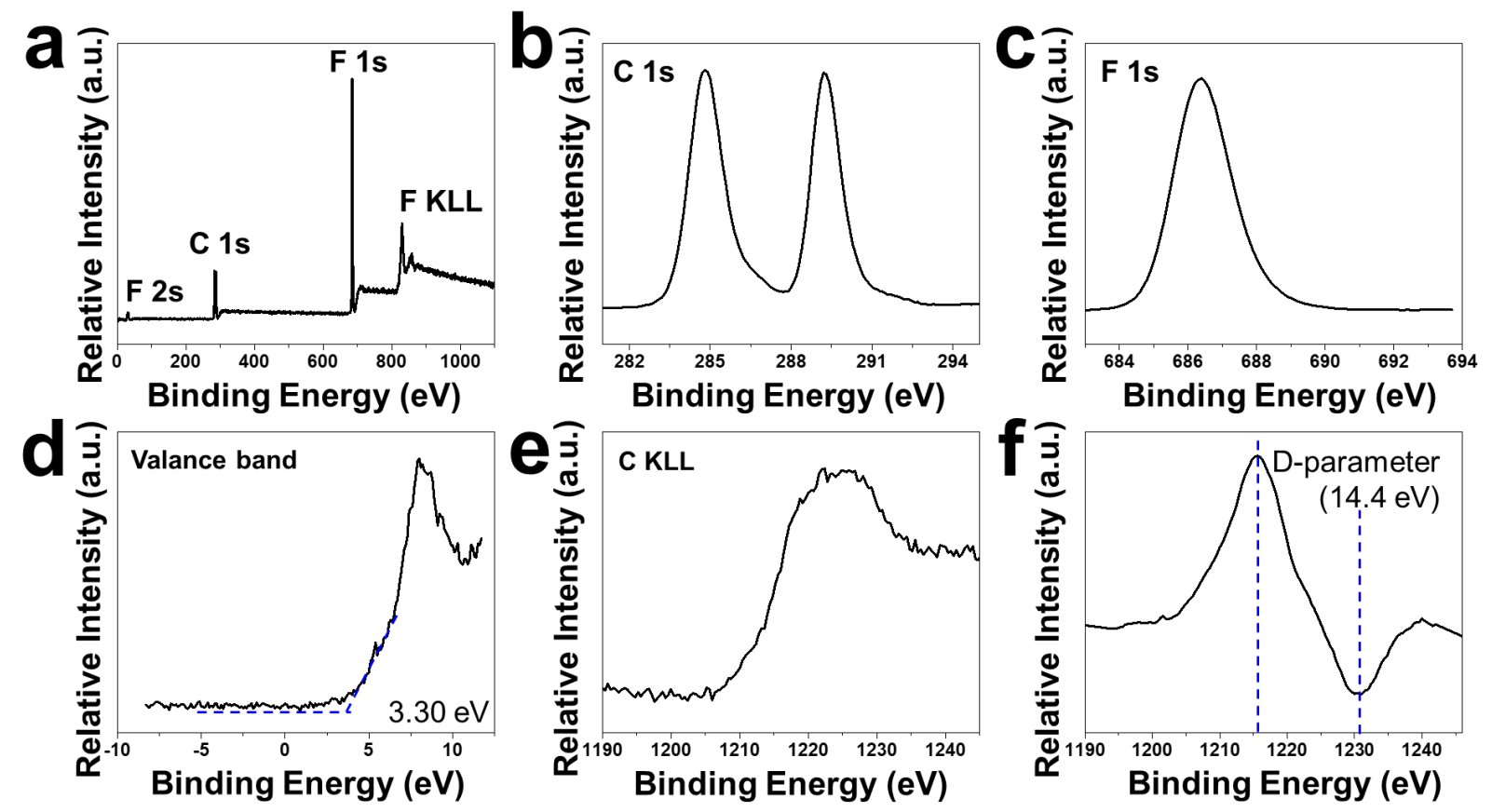

Figure S12. The XPS analysis of the PVDF reactant. (a) XPS spectrum of PVDF reactant. High resolution XPS spectra of (b) C 1s, (c) F 1s, (d) valance band and (e) C KLL of PVDF reactant. (f) The derivative curve of the C KLL spectrum in (e). As shown in Figure S12 and Table S1, there was $\sim 50.5 \%$ carbon and $49.5 \%$ fluorine. In C $1 \mathrm{~s}$ spectrum, the peak centered at $289.3 \mathrm{eV}$ belongs to the covalent C-F bonds in the PVDF. Compared to PTFE, the binding energy of F was lower in PVDF ( 686.3 eV) which indicates higher electron density of F atoms in PVDF and semi-ionic component in the C-F bonds. The VB-XPS in Figure S12d shows the existence of a wide band gap with value $\sim 3.30 \mathrm{eV}$ and the D parameter was $14.4 \mathrm{eV}$ as shown in Figure S12f that indicates a large proportion of $\mathrm{sp}^{3}$-carbon in the reactant. 

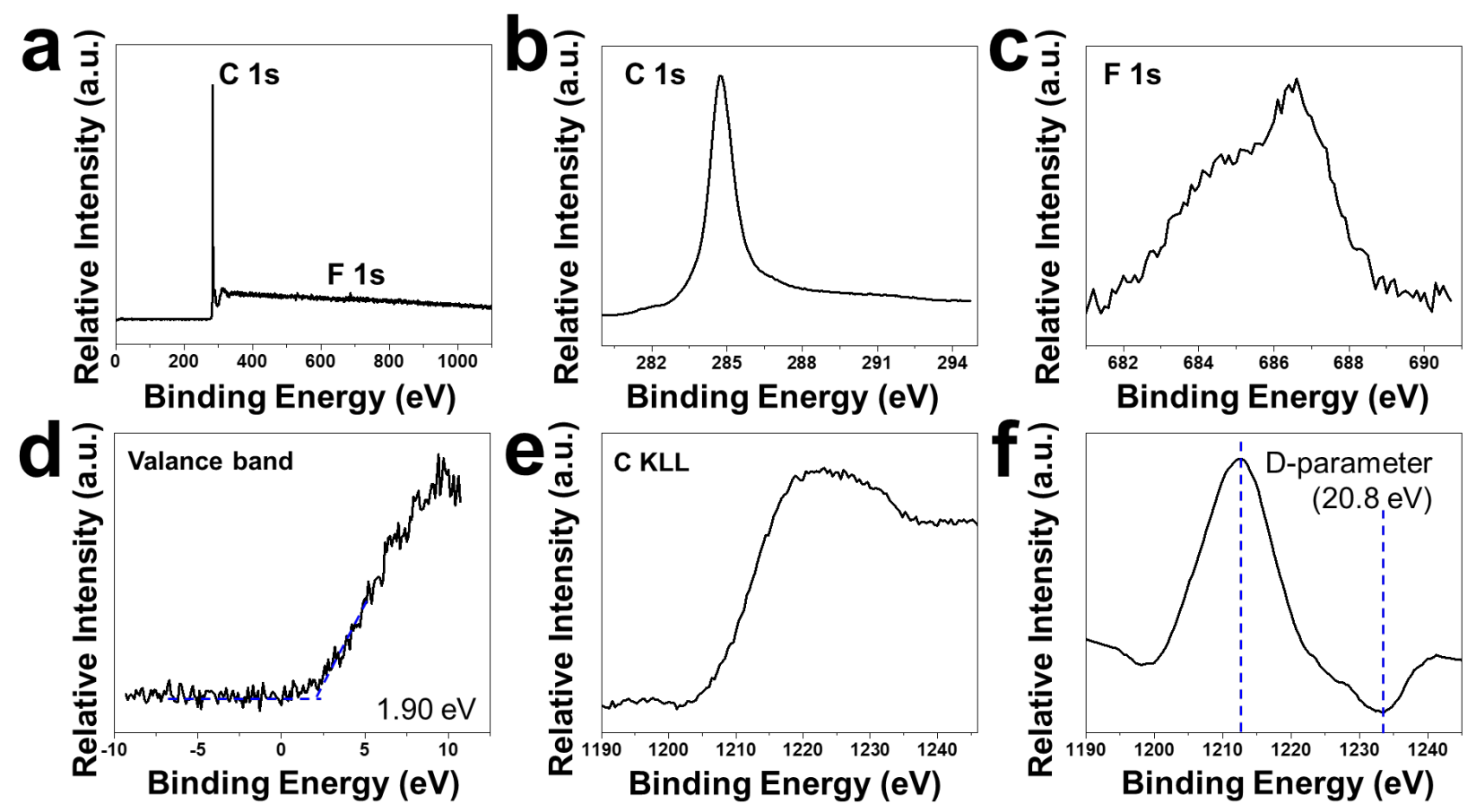

Figure S13. The XPS analysis of flash product derived from PVDF with $20 \mathrm{wt} \%$ CB. (a) XPS survey spectrum of the flash product derived from PVDF with $20 \mathrm{wt} \% \mathrm{CB}$. High resolution XPS spectra of (b) C 1s, (c) F 1s, (d) valance band and (e) C KLL of the flash product derived from PVDF with $20 \mathrm{wt} \% \mathrm{CB}$. (f) The derivative curve of the C KLL spectrum in (e). As shown here, there was $\sim 98.3 \%$ carbon and $0.9 \%$ fluorine. In the F $1 \mathrm{~s}$ spectrum, the semi-ionic C-F bonds dominate $(\sim 686.1 \mathrm{eV})$, and there is little covalent C-F $(\sim 689.5 \mathrm{eV})$. The VB-XPS in Figure S13d shows the existence of a wide band gap with value $\sim 1.90 \mathrm{eV}$, which could result from the formation of semi-ionic C-F bonds in the graphite structure. The D parameter was $20.8 \mathrm{eV}$ as shown in Figure $\mathrm{S} 13 \mathrm{f}$ which also indicates a large portion of $\mathrm{sp}^{2}$-carbon in the sample. 

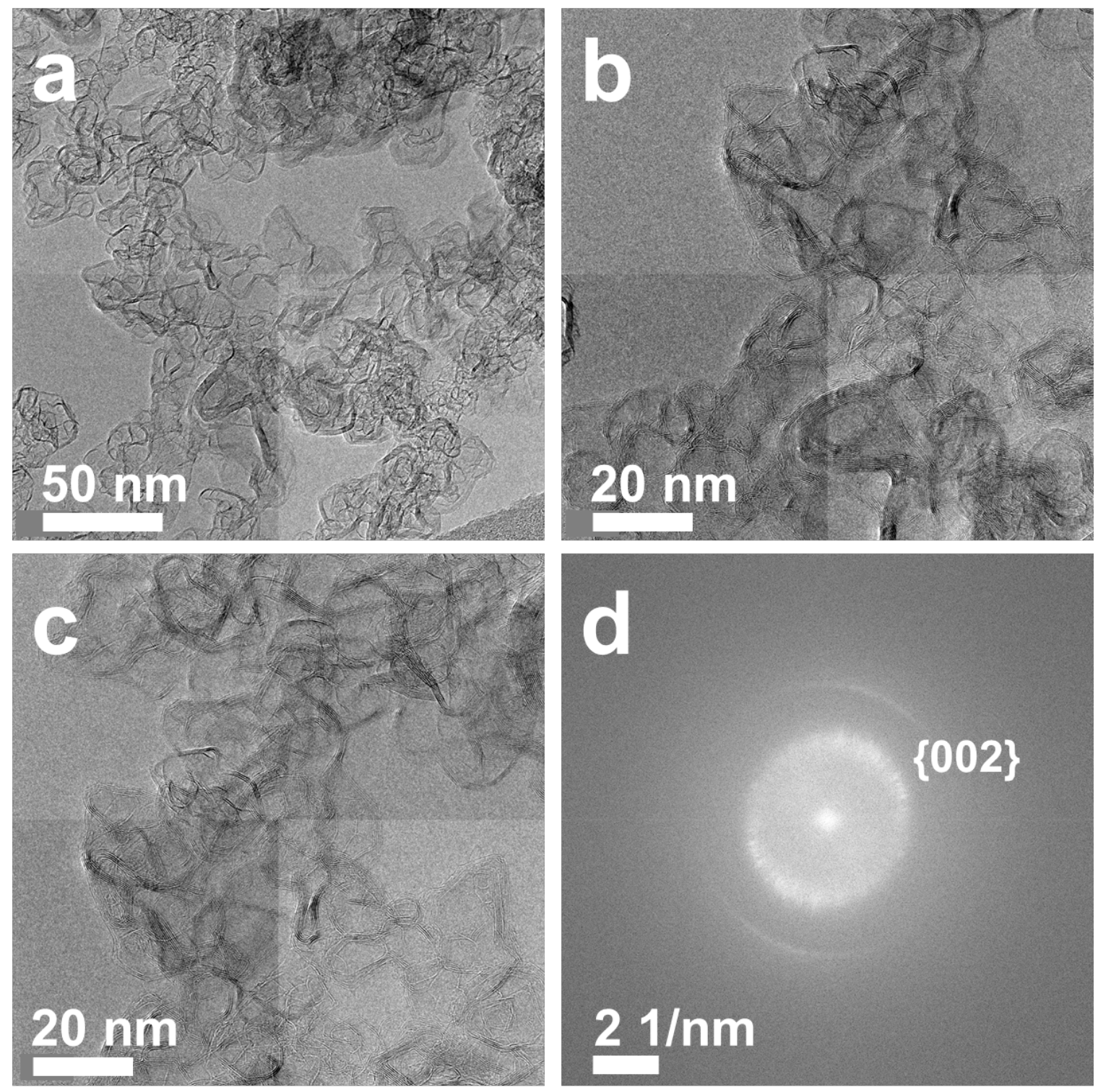

Figure S14. Microscopic analysis of carbon materials with different reactants. The reactant is CB. (a-c) TEM images of the FG materials and (d) corresponding FFT result. 

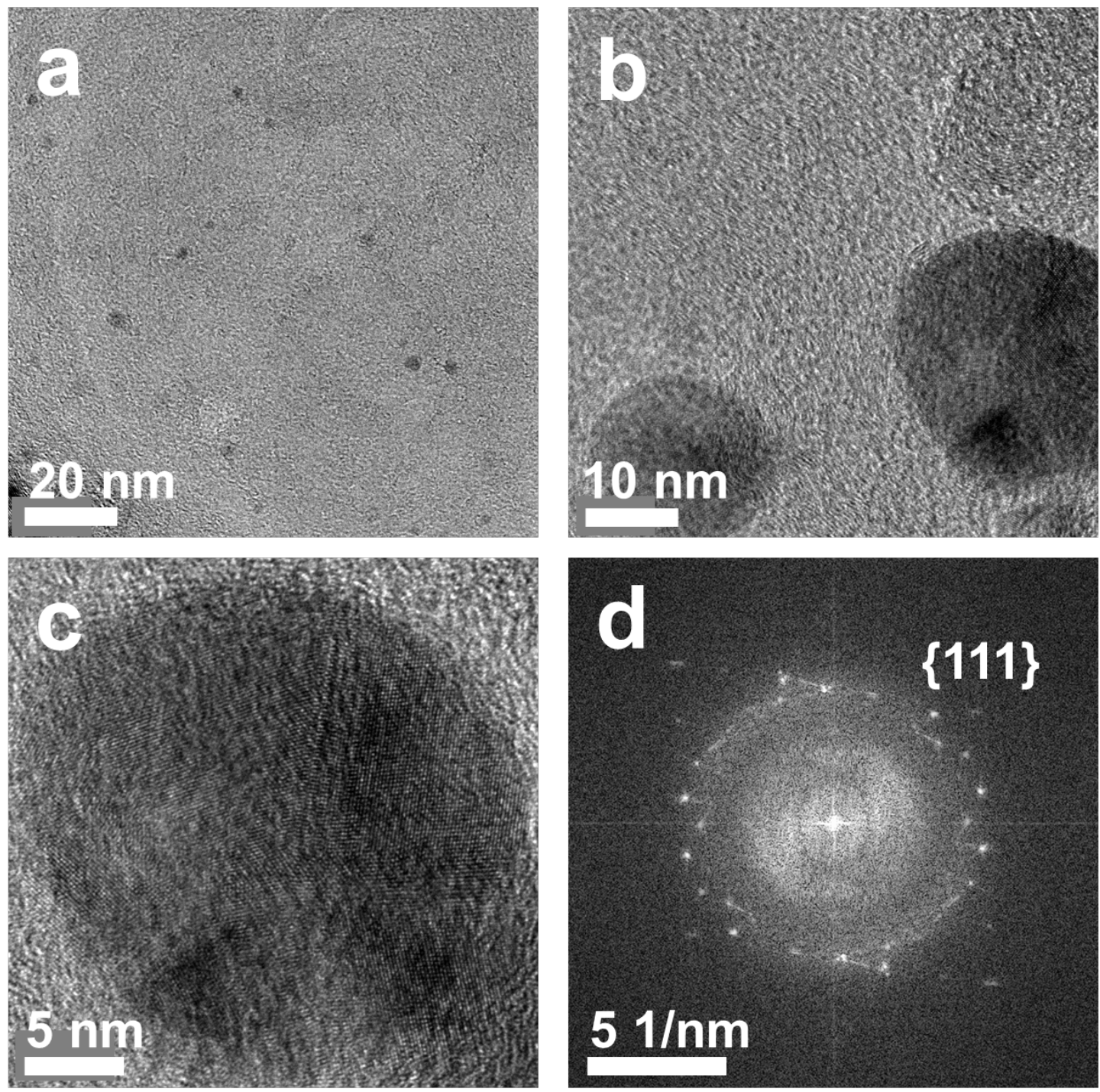

Figure S15. Microscopic analysis of carbon materials with different reactants. The reactant is PTFE with 20 wt $\%$ CB derived FG. (a-b) TEM images of the NDs. (c) HR-TEM images of ND materials and (d) corresponding FFT result. FG can be also used as a conductive additive in the flash reaction. The FND can be seen in the TEM images as shown in Figure S15a-b. The HR-TEM image shows the crystal structure of the FNDs and the twin plane of the diamond crystal can be seen (the black ridges as shown in Figure S15c). As a consequence, there are several orientations for the crystal and many different sets of Bragg spots in FFT result as in (d). 

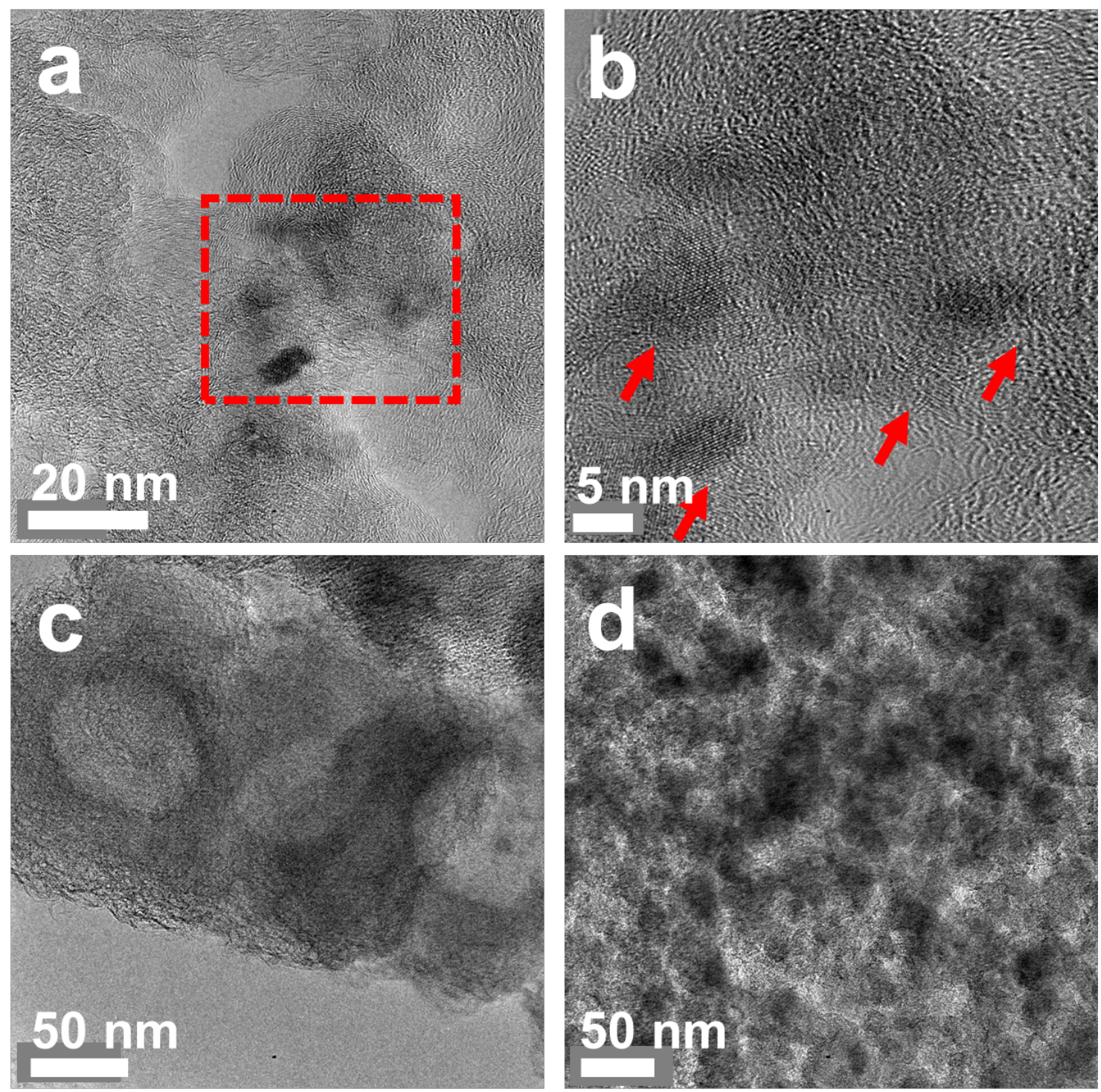

Figure S16. Microscopic analysis of carbon materials with different reactants. The reactant is PTFE with $20 w t \%$ CB and $10 w t \%$ NaF. (a) TEM image of the distribution of the NDs. (b) HRTEM image reporting the NDs embedded on the amorphous carbon substrate. The NDs are indicated by the red arrows in the images. (c) and (d) TEM images show the etching effect of the $\mathrm{NaF}$ additive. $\mathrm{NaF}$ facilitates the etching effect during the flash reaction; if a quartz tube is used in the experiment, the inner wall of the tube will be etched by the gas products, which might be $\mathrm{HF}_{(\mathrm{g}) \text {. }}$ 
There is no evidence to show the addition of NaF can be beneficial to the growth of larger NDs with higher densities.
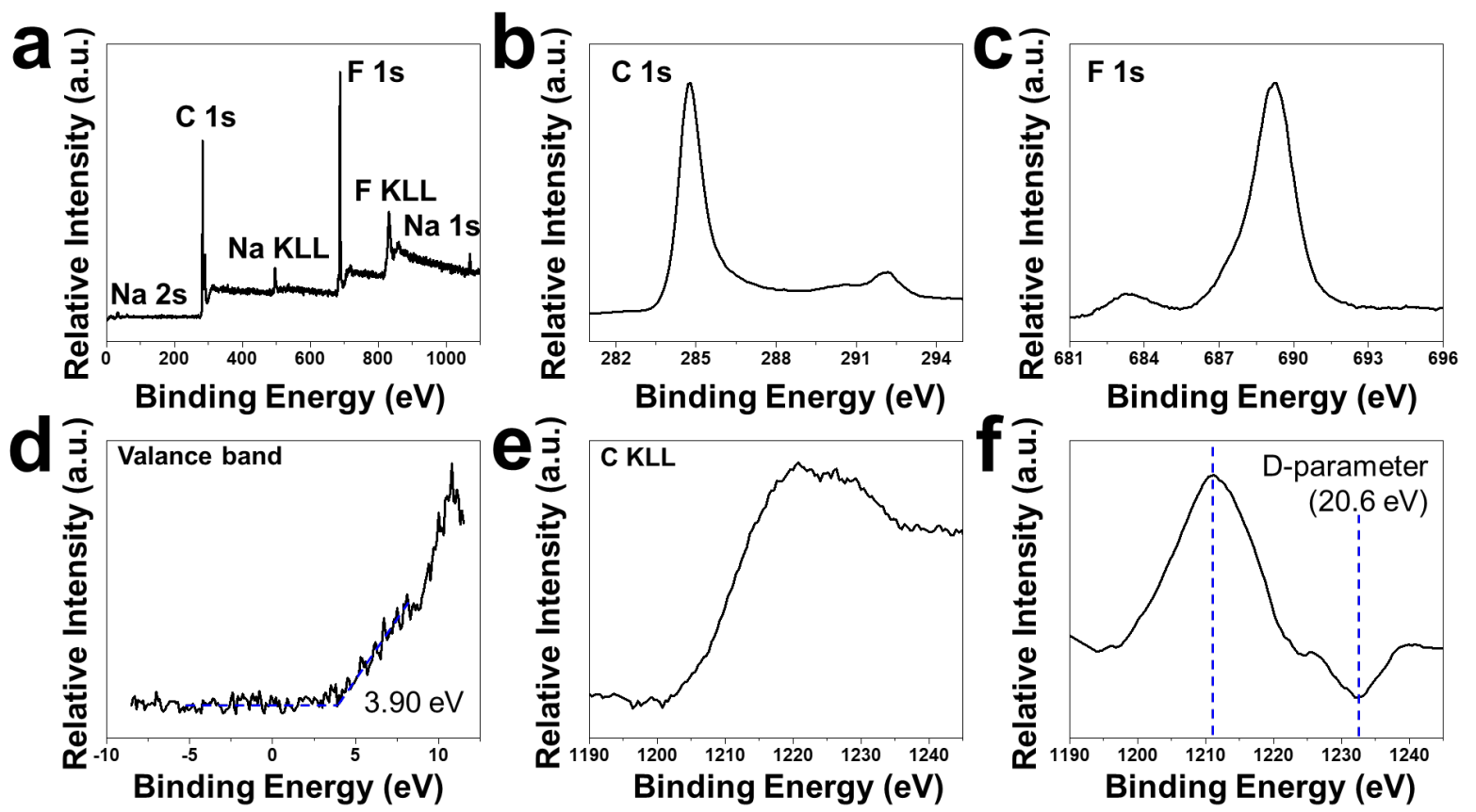

Figure S17. The XPS analysis of flash product after adding NaF. (a) XPS spectrum of flash product derived from PTFE with $20 \mathrm{wt} \% \mathrm{CB}$ and $10 \mathrm{wt} \% \mathrm{NaF}$. High resolution XPS spectra of (b) C 1s, (c) F 1s, (d) valance band and (e) C KLL of flash product derived from PTFE with $20 \mathrm{wt} \%$ $\mathrm{CB}$ and $10 \mathrm{wt} \% \mathrm{NaF}$. (f) The derivative curve of the C KLL spectrum in (e). 

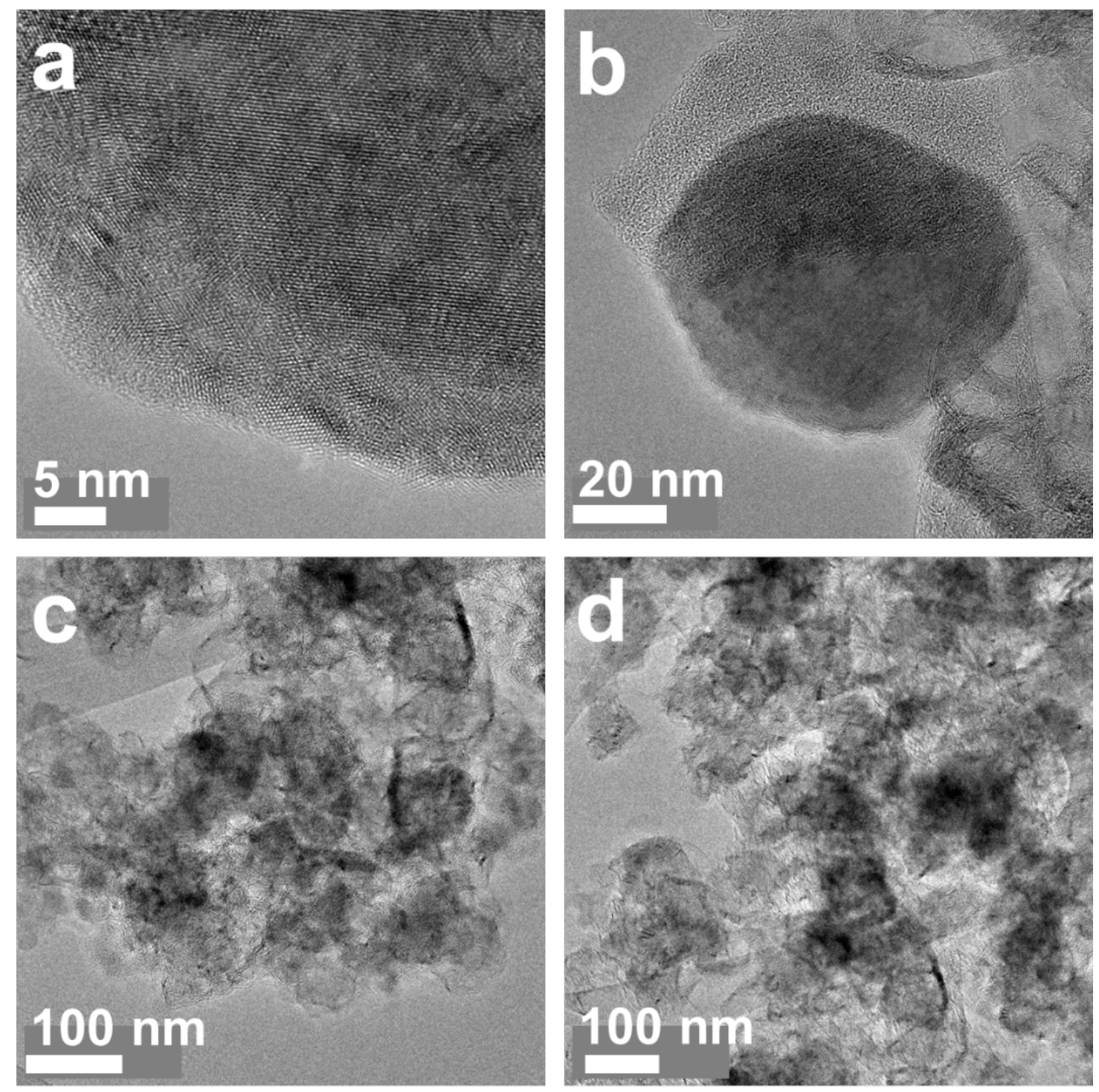

Figure S18. Microscopic analysis of carbon materials with different reactants. The reactant is

1H,1H-perfluoro-1-dodecanol with $20 \mathrm{wt} \% \mathrm{CB}$. (a) HR-TEM image showing the polycrystallinity of NDs. (b) TEM image of a ND particle with the size $\sim 80 \mathrm{~nm}$. (c-d) TEM images of the distribution of the NDs. 

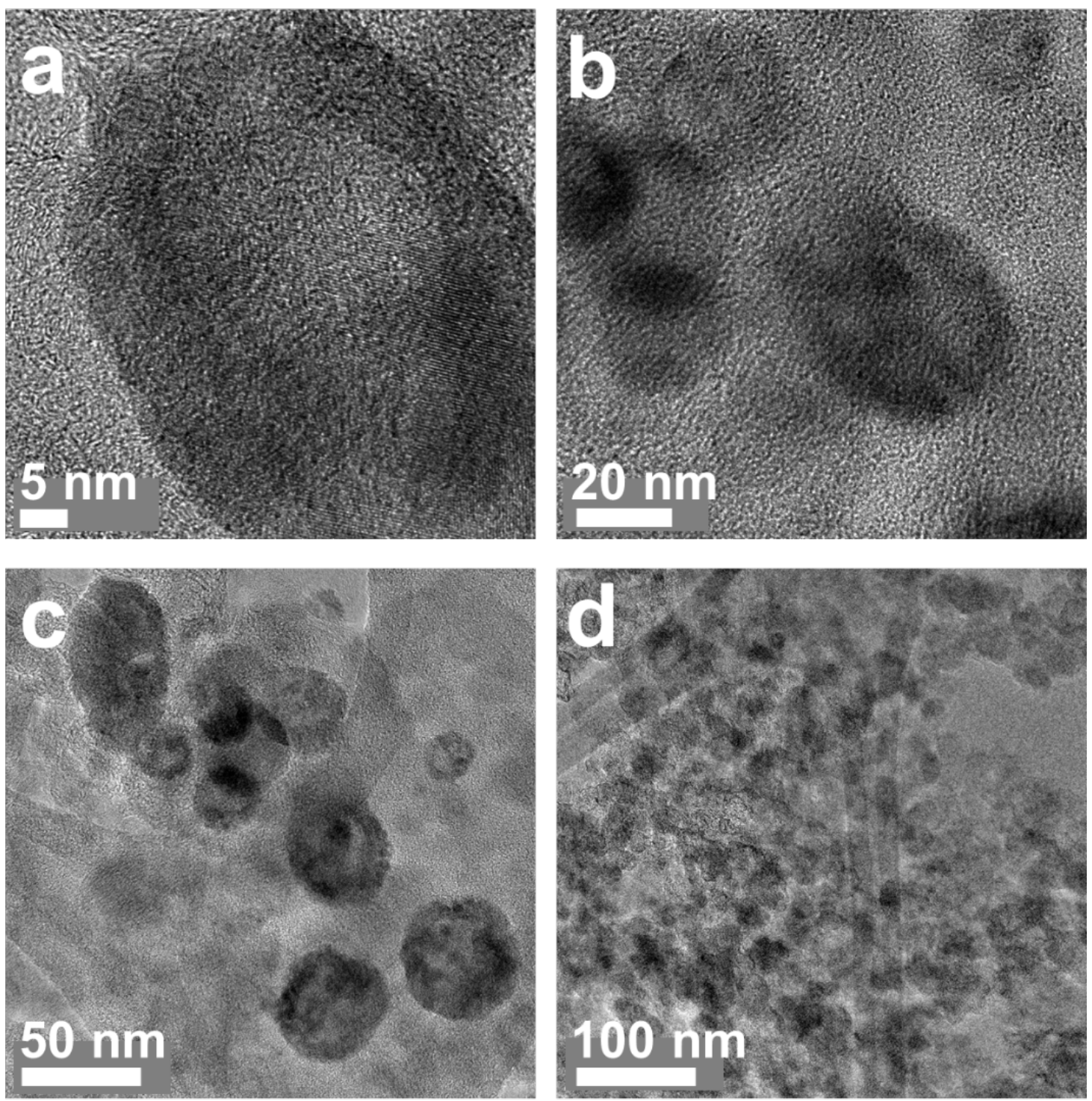

Figure S19. Microscopic analysis of carbon materials with different reactants. The reactant is 1,1,1,2,2,3,3,4,4,5,5,6,6,7,7,8,8-Heptadecafluoro-10-iododecane with $20 \mathrm{wt} \%$ CB. (a) HR-TEM image reporting the NDs embedded on the amorphous carbon substrate. (b) TEM image of a ND particle with the size $\sim 60 \mathrm{~nm}$. (c-d) TEM images of the distribution of the NDs.

Effect of flash duration on phase evolution of carbon materials 

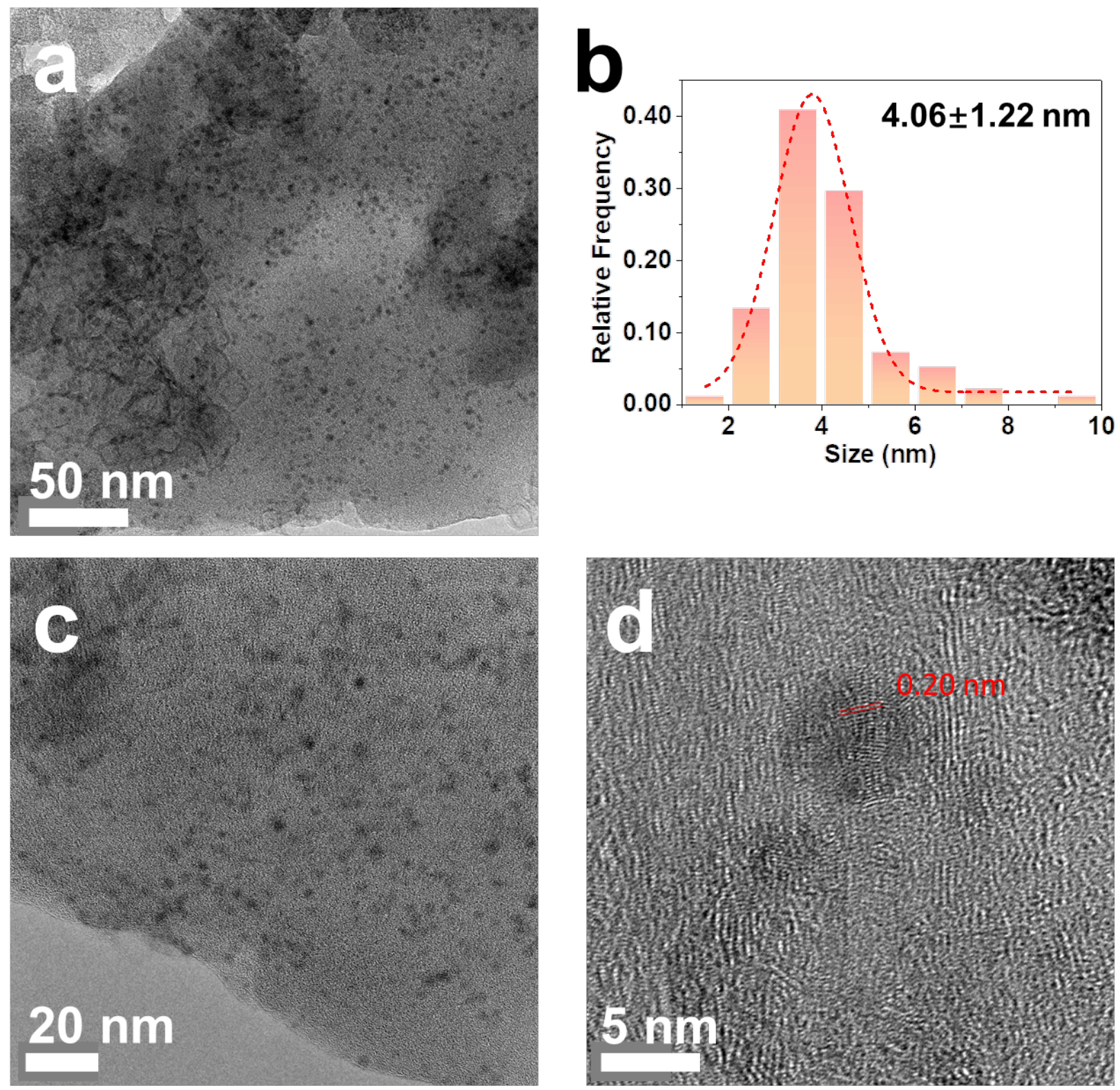

Figure S20. Microscopic analysis of carbon materials at the second stage. (a) TEM images and (b) the corresponding statistical survey of the FND sizes, $\mathrm{N}=100$. (c, d) HR-TEM images of FNDs at the second stage. As shown in Figure S20a, the formation of the FFG and small FNDs can be seen, which verified the proposed mechanism as shown in Figure $6 \mathrm{~b}$. The average size of the 100 individual FNDs is $4.06 \mathrm{~nm}$. From the HR-TEM image, the $\{111\}$ plane with spacing $\sim 0.20 \mathrm{~nm}$ can be seen and these FNDs are surrounded by amorphous carbon, which might be beneficial to lower surface energy and facilitate structural stability during the flash reaction. 

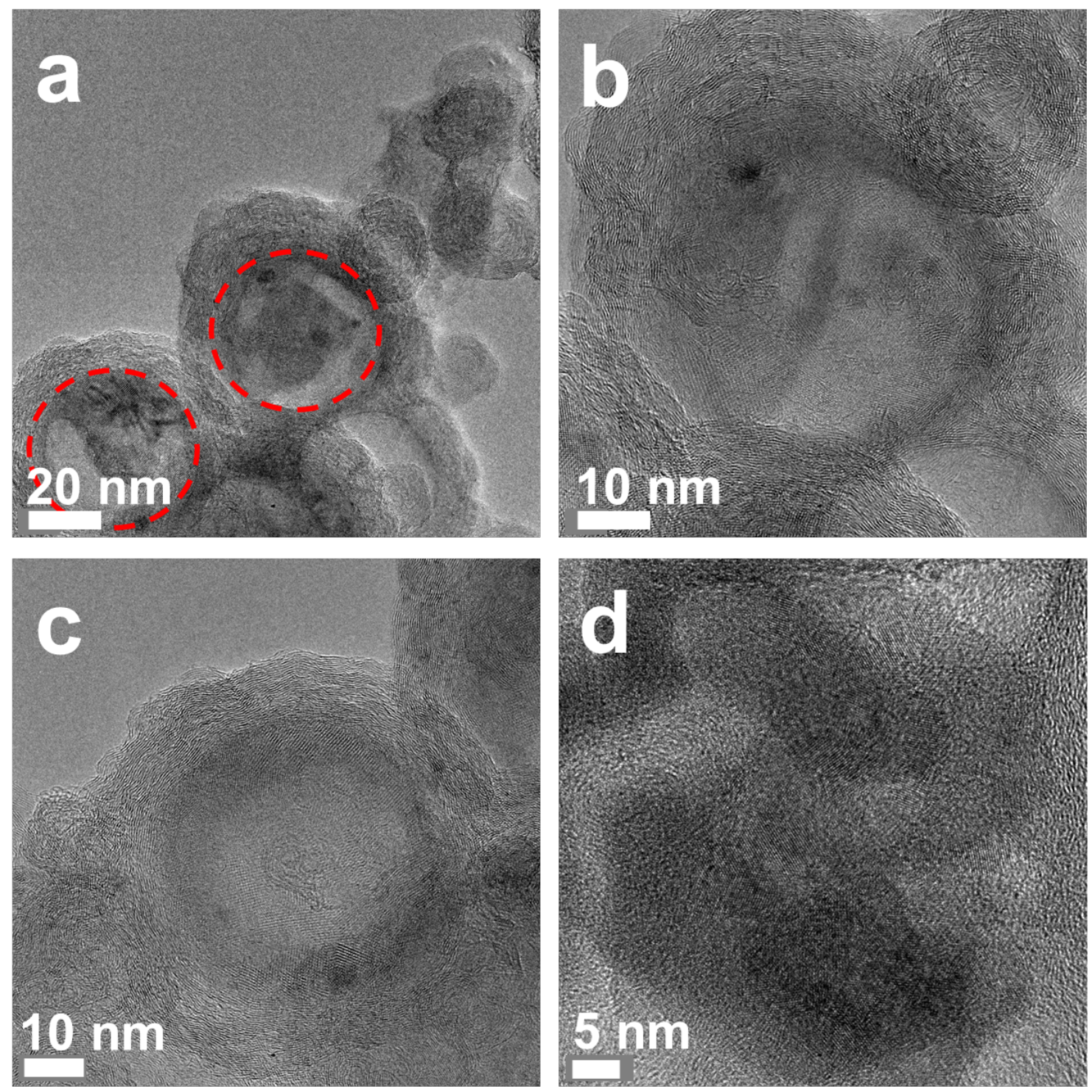

Figure S21. Microscopic analysis of carbon materials at intermediate stage. (a) TEM image of FND enclosed by graphene shells. The boundary is indicated by the red dashed circles. (b, c) HRTEM images of FNDs enclosed by graphene shells. (d) HR-TEM images of FND with various random orientations. As proposed in Figure 6, the graphitization of the FNDs occurred from the outermost surface. The surface graphitization of the FNDs can be identified by the lattice fringes which belong to graphene (002) planes. As shown in Figure 1c, the initial stage of surface 
graphitization with a few-layer discontinuous graphene shell can be distinguished. Then the fragments of the graphitized region on the surface can merge and form the FCC shells with polyhedral shape at the outer surface. The progress of graphitization moves to the interior of the FND particles and the thickness of the graphitized structure increases as shown in Figure S21. FND particles are converted into the FCC with highly graphitized structure at the final stage as shown in Figure 5 and 6.

\section{References}

1. Luong, D. X.; Bets, K. V.; Algozeeb, W. A.; Stanford, M. G.; Kittrell, C.; Chen, W.; Salvatierra, R. V.; Ren, M.; McHugh, E. A.; Advincula, P. A.; Wang, Z.; Bhatt, M.; Guo, H.; Mancevski, V.; Shahsavari, R.; Yakobson, B. I.; Tour, J. M. Gram-Scale Bottom-Up Flash Graphene Synthesis. Nature 2020, 577, 647-651.

2. Chen, W.; Wang, Z.; Bets, K. V.; Luong, D. X.; Ren, M.; Stanford, M. G.; McHugh, E. A.; Algozeeb, W. A.; Guo, H.; Gao, G.; Deng. B.; Chen, J.; Li, J. T.; Carsten, W. T.; Yakobson, B. I.; Tour, J. M. Millisecond Conversion of Metastable 2D Materials by Flash Joule Heating. ACS Nano 2021, 15, 1282-1290.

3. Algozeeb, W. A.; Savas, P. E.; Luong, D. X.; Chen, W.; Kittrell, C.; Bhat, M.; Shahsavari, R.; Tour, J. M. Flash Graphene from Plastic Waste. ACS Nano 2020, 14, 15595-15604.

4. Sajid, M.; Ilyas, M. PTFE-Coated Non-Stick Cookware and Toxicity Concerns: A Perspective. Environ. Sci. Pollut. Res. 2017, 24, 23436-23440.

5. Stanford, M. G.; Bets, K. V.; Luong, D. X.; Advincula, P. A.; Chen, W.; Li, J. T.; Wang, Z.; McHugh, E. A.; Algozeeb, W. A.; Yakobson, B. I.; Tour, J. M. Flash Graphene Morphologies. ACS Nano 2020, 14, 13691-13699. 
6. Ye, R.; Han, X.; Kosynkin, D. V.; Li, Y.; Zhang, C.; Jiang, B.; Marti, A. A.; Tour, J. M. Laser-Induced Conversion of Teflon into Fluorinated Nanodiamonds or Fluorinated Graphene. ACS Nano 2018, 12, 1083-1088. 